pointing out that it is a research institution which has no collective opinions.

\section{Hospital Physicists' Association}

AN inaugural meeting of the new Hospital Physicists' Association, held by courtesy at the British Institute of Radiology on September 24, was attended by thirty-seven physicists drawn from hospitals all over Great Britain. The aims of the new Association are to discuss matters arising out of the mutual interests of those engaged in a branch of scientific work which has grown up largely in the last thirty years. Membership is open to physicists attached to hospitals, medical schools, medical or biological research departments. The meeting was followed by visits to the Middlesex, Royal Cancer and Westminster Hospitals on the next day. The afternoon session was devoted to papers. Dr. H. T. Flint spoke on technique with the various radium gramunits; Prof. F. L. Hopwood gave an account of the betatron; Prof. G. Stead discussed teaching for the diplomas and Prof. S. Russ read a paper on the professional equipment of a hospital physicist. Messages of goodwill from the National Radium Commission and the Council of the British Institute of Radiology were read at the meeting. It was agreed that there should be at least three meetings during the year, one of which should be in the provinces. Prof. Russ was elected chairman for the first year, with Dr. Wilson of Westminster Hospital acting as honorary secretary. Prof. Russ reminded his audience that the first full-time appointment as physicist to the Hospital was made thirty years ago. It is likely that to-day between fifty and sixty physicists were engaged in some capacity in hospital or medical research work. A good start was made with the new Association with plenty of evidence of vitality among its members.

\section{Post-War Building Policy}

A PAPER, "Housing, Town Planning and Full Employment" by F. J. Osborn, which has been reprinted from Town and Country Planning, points out that while the method of compartmental study of housing policy, town and country planning policy and building industry policy is essential owing to the complexity of the subject as a whole, there must also be co-ordination at a high level before major policy decisions are taken. There are, however, ominous signs of different accentuations and of a clash not far ahead. In particular, Mr. Osborn points out that the Minister of Health's housing circular of March 4 is reactionary in its planning implications, and if the local authorities act upon it before a planning policy is announced it will prejudice that policy and preclude its taking the new direction which the Government has been contemplating.

Analysing the building programmo to which the Government has been committed by its White Paper of February last, Mr. Osborn considers that the programme is practical in terms of man-power, of labour, of materials, of finance, and suggests that the main difficulty will be the partly, but not wholly, obsolete dwelling. The White Paper programme cannot be carried out without the replacement of nearly all the pre-1914 dwellings in our old towns and villages. Where vacant sites are available nearby, the procedure could be fairly simple. Either the local authority could build or the Government could encourage private enterprise to do so by offering finance on suitable terms. In areas of high concentration this will not be effective, as many old houses will still have a rental value which will persist longer than twenty or twenty-five years. Consequently the total cost after rebuilding will be the present value and the cost of the new buildings which will replace them, and since these costs added together will make the rent of the rebuilt dwellings too high, the obsolete dwellings will still stand.

Mr. Osborn sees only three methods by which this obstacle could be overcome. One of these he rejects - the State to find the money for buying out the existing values of obsolescent dwellings and cancelling them, so that the sites can be cleared for economic re-building at low density. In his view a combination of the other two will be necessary : the employment of a substantial part of the building industry both by the State and by private enterprise under State stimulus in creating entirely new centres of life and work, and planned extensions of existing small towns; and third, to set statutory limit on the life of an old dwelling, a principle which is included in the Uthwatt proposals. $\mathrm{H}_{\Theta}$ urges the desperate urgency of a planning policy and the necessity of facing squarely the problems of obsolescence of urban buildings and compensation for land values, and creating the machinery for controlling the location of industry and business, and for building new towns and town-extensions to relieve the pressure on space where the bulk of rebuilding has to be done.

\section{Increase in American Longevity}

According to the April issue of the Statistical Bulletin, the organ of the Metropolitan Life Insurance Company of New York, the average length of life of the American people has increased by almost one third since the beginning of the century. In 1941 the average expectation of life at birth was $64 \cdot 36$ years, which was a gain of more than fifteen years since 1901. The record was especially favourable for white females, who in 1941 had attained an average length of life of $68 \cdot 08$, as compared with $63 \cdot 39$ years for white males. Coloured persons showed a greater longevity than the white, though the current longevity among the coloured was still ten years less than for the white. The most substantial gain in longevity occurred in childhood, adolescence and young adult life, the death-rates in 1941 below forty being well under one half those at the beginning of the century. Improvements in mortality have also taken place even after forty. The favourable health situation is also illustrated by the fact that about 60 per cent of the babies now being born will live to 65 as compared with only 40 per cent in 1901. On the whole, health conditions have been very favourable in spite of the growing shortage of civilian medical men, the initiation of restrictions on food consumption, the crowding in centres of war industries and inadequate housing.

\section{Conservation of Wild Life in Great Britain}

THe Universities' Federation for Animal Welfare (temporary address, 284 Regent's Park Road, London, N.3) has issued a circular directing attention to the need for co-ordinating the diverse and often conflicting interests concerned with the regulation of wild life, both fauna and flora, in Great Britain. It is suggested that a central "Wild Life Authority" should be set up by statute and charged with the 
duty cf studying and directing all measures necessary for the control of injurious, and the conservation of desirable, species. Except that the Federation is specially concerned to urge the adoption of humane methods in the destruction of animal pests, its aims seem to differ little from those of several other existing organizations, such as those concerned with national parks, nature reserves, and the like. Further discussion will doubtless emphasize the importance of co-operation rather than competition in this, as in so many other schemes for post-war progress.

\section{Inter-allied Bureau for Educational Reconstruction}

Aw the sixth meeting of the Conference of Ministers of Education of the Allied Governments held at the offices of the Board of Education on October 5 , it was agreed to establish an Inter-Allied Bureau to carry out the practical steps needed to restore educational services in the countries concerned. This Bureau will be the executive body of the Conference. The work to be undertaken by the Bureau includes the purchase and distribution of books and periodicals, the preparation of films and other visual aids and the supply of scientific equipment. These matters are at present being considered by commissions of the Conference. The Bureau was also asked to consider financial needs and methods of contribution by Governments and the establishment of an inter-Allied secretariat.

\section{Recent Earthquakes}

The United States Coast and Geodetic Survey, in co-operation with Science Service and the Jesuit Seismological Association, has determined the epicentres of four recent earthquakes. These are in scattered localities but are all in areas where earthquakes are known to be relatively frequent. The first was on July 23,1943 , at $15 \mathrm{~h}$. $52.9 \mathrm{~m}$. U.T. and occurred near lat. $10 \cdot 5^{\circ} \mathrm{S}$, long. $117 \cdot 5^{\circ} \mathrm{E}$. This is in the Indian Ocean south of the island of Soembawa, approximately between Java and Australia. The next two came from the same epicentre, the second thus being an aftershock of the first, and together showing the tendency of earthquakes to recur from the same epicentre. The first of these was on July 29, at $3 \mathrm{~h} .02 \mathrm{~m} .14 \mathrm{~s}$. U.T., from an epicentre noar lat. $18 \cdot 9^{\circ} \mathrm{N}$., long. $67^{\circ} \mathrm{W}$., which is in the Atlantic Ocean between Nares Deep and tho island of Puerto Rico and north of the latter. The aftershock occurred on the next day, July 30 , at $1 \mathrm{~h} .02 \mathrm{~m}$. $32 \mathrm{~s}$. U.T. from the same epicentre in the West Indies. The fourth earthquake oceurrod on August 10 at 15h. $13.3 \mathrm{~m}$. U.T. from an epicentre near lat. $54^{\circ} \mathrm{N}$,, long. $161^{\circ} \mathrm{F}$., which is approximately in the middle of the east coast of the Kamchatka Peninsula and midway ketween the towns of Ust-Kamchatsk and Petropavlovsk-Kamchatski. The east coast of the Kamchatka Peninsula forms part of the circum-Pacific chain of instability, lying between the Japanese Islands and the Aleutian Islands. The depths of focus of all four earthquakes are considered normal and the interpretations and calculations are tentative. Data were received from seismological observatories in North and South America, Honolulu, New Zealand and Australia.

\section{Comet Oterma (1943a)}

As orbit for Comet Oterma, 1943a, has been computed, and its eccentricity is only a little more than half that of Pluto. As a result of this small eccentricity, it will be possible to observe the comet easily throughout its orbit. This is the second comet so far discovered which possesses this distinction, the other comet being Schwassmann-Wachmann (1925, ii). The eccentricities are 0.139 for Comet $1943 \alpha$ and 0.142 for Comet 1925, ii ; but the periods are very different, namely, 8 years and $16 \cdot 3$ years respectively.

The elements of the orbit of Comet Oterma are given kelow, but as it is at a considerable distance from the sun and the earth, it is not an easy object except for moderate-sized telescopes.

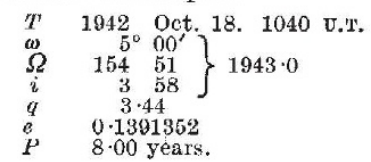

\section{Nova Aquilæe}

A TELEGRAM from Copenhagen announces that this nova attained magnitude 7 at the outburst between April 13 and May 2. Its position, referred to the equinox of 1855 , is R.A. $19 \mathrm{~h} .45 \cdot 5 \mathrm{~m}$., Dec. $8^{\circ} 06^{\prime} \mathrm{N}$. It is a little brighter than magnitude 12 at present.

\section{Announcements}

MR. J. BENSTEAD, general secretary of the National Union of Railwaymen, and Mr. E. Thornton, secretary of the United Textile Factory Workers Association and secretary of the Rochdale Weavers' Association, have been appointed members of the Advisory Council to the Committee of the Privy Council for Scientific and Industrial Research. Sir John Greenly retired from the Council on completion of his term of office on Septemter 30.

THe College of Physicians of Philadelphia has awarded the Alvarenza Prize to Dr. Ernest Carroll Faust, professor of medical parasitology and acting head of the Department of Tropical Medicine, Tulane University, for his "outstanding contributions to our knowledge of parasitology and tropical medicine".

THE centenary meeting of the Royal Anthropological Institute will be held on October 30. Prof. J. H. Hutton, president of the Institute, will preside, and addresses will be delivered by Sir John Myres on the work of the Institute, and by Lord Hailey on "The Role of Anthropology in Colonial Develop. ment" during the morning. The aftornoon meeting will take the form of a symposium on "The Future of Anthropology", in which Dr. G. M. Morant will speak on physical anthropology, Prof. V. G. Childe on archæulogy, Mr. R. U. Sayce on material culture and Prof. R. Firth on social anthropology. The morning meetings will be at the rooms of the Royal Society and the afternoon meetings at the Institute.

The Nutrition Society has arranged a whole-day conference on "Post-war Nutritional Relief", at the London School of Hygiene and Tropical Medicino, Keppel Street, W.C.I, on November 6. The chair will be taken by Lord, Horder and papers will be read by Prof. J. R. Marrack ("Past Experience and Present Position"), Dr. J. Hammond ("Problems of Production in Relation to Post-war Nutritional Relief"), Miss E. M. M. Hume ("Opportunities for Nutritional Research in the Work of Relief") and others. Details of this meeting can be obtained from the hon. secretary, Dr. Leslie J. Harris, Nutritional Laboratory, Milton Road, Cambridge. 